\title{
Damage Evaluation of a Welded Joint in a Long-term Service- exposed Boiler by Using a Small Punch Creep Test
}

\author{
Shin-ichi KOMAZAKI, ${ }^{11}$ Takayuki SUGIMOTO, ${ }^{2)}$ Yasushi HASEGAWA ${ }^{31}$ and Yutaka KOHNO ${ }^{11}$ \\ 1) Department of Materials Science and Engineering, Muroran Institute of Technology, Muroran 050-8585 Japan. \\ 2) Formerly Department of Materials Science and Engineering, Muroran Institute of Technology. Now at Nikko Inspection \\ Service Co., Ltd., 4-1 Chatsu-machi, Muroran 051-8505 Japan. 3) Steel Research Laboratories, Nippon Steel Corporation, \\ Futtsu 293-8511 Japan.
}

(Received on April 9, 2007; accepted on May 23, 2007)

\begin{abstract}
A small punch (SP) creep test was applied to the welded joint of a boiler header (1.0 Cr-0.3Mo steel), which had been actually used for around $250000 \mathrm{~h}$, to evaluate the changes in creep properties. A miniaturized plate-type specimen of $10 \times 10 \times 0.5 \mathrm{~mm}$ was taken from the base metal, weld metal and the heat affected zone (HAZ), respectively, for the SP creep test and microstructure observation. Experimental results revealed that the creep rupture strength of each portion had decreased by long-term service exposure, especially in the high stress (load) conditions. The creep rupture time of the HAZ was shorter than that of the base and weld metals in the low stress (load) levels, suggesting the possibility of Type IV creep damage. TEM observation also revealed that film-like $(\mathrm{Mo}, \mathrm{Fe})_{6} \mathrm{C}$ carbides precipitated along the grain boundaries in the $\mathrm{HAZ}$, as well as the coarsening of the $\mathrm{M}_{23} \mathrm{C}_{6}$ carbides. These microstructural changes were likely to cause the above-mentioned reduction in the creep rupture strength at the HAZ.
\end{abstract}

KEY WORDS: SP creep test; creep; damage evaluation; remaining-life prediction; type IV damage; welded joint; heat affected zone.

\section{Introduction}

In Japan, nearly seventy-five percent of fossil fuel power plants have been already operated over $100000 \mathrm{~h}$ and are so-called aged plants. ${ }^{1)}$ From economic perspectives, however, their lifespan must be extended. Meeting this requirement will involve evaluating the material degradation of high-temperature components, in particular, their welded joints, which used to be the most critical portion, in order to operate them while maintaining high integrity. On the other hand, premature failures at the outer edge of heat affected zone (HAZ) of the welded joint, which is known to be "Type IV creep damage", has recently been the most serious problem in advanced high chromium ferritic steels. ${ }^{2,3)}$ This damage occurs to fine grain HAZ, forming microvoids, and is closely associated with microstructural changes attributable to the welding thermal cycle and the subsequent operating history. ${ }^{4,5)}$ In general, to measure the creep properties and the failure behaviors of HAZ, standard or miniaturized specimens (cross weld samples) are removed from the welded joint so that the weld metal or HAZ is located at the center of the gauge portion. However, it is difficult to evaluate the creep properties of such a local and limited HAZ alone, because the creep deformation takes place on the base and weld metals as well as the HAZ. Additionally, the fracture does not always occur at the HAZ. A simulated $H_{A} Z^{6,7)}$ is often applied when the properties of $\mathrm{HAZ}$ are required, but it is by no means easy to completely simulate the microstructure of HAZ, which is formed by complicated welding thermal cycles.

In the late 1970 s and early 1980 s, the small punch (SP) testing method was developed in order to measure the ductile-brittle transition temperature (DBTT) ${ }^{8-10)}$ and estimate the fracture toughness ${ }^{11,12}$ and thermal aging embrittlement ${ }^{13-15)}$ via a miniaturized plate-type specimen $(10 \times$ $10 \times 0.5 \mathrm{~mm}$ or $\phi 3 \times 0.25 \mathrm{~mm})$. The SP testing method is also applied to evaluating the susceptibility to environmental embrittlement, such as stress corrosion cracking and hydrogen embrittlement. ${ }^{16,17)}$ It has recently been employed in measuring high-temperature creep properties of heat-resistant materials ${ }^{18-21)}$ and is also considered viable as a new procedure for assessing the degradation and remaining-life of aged components in fossil fuel power plants. Application of the current SP creep test is anticipated for the measurement of the HAZ creep properties, because the specimen volume is smaller than that of conventional miniaturized creep specimens. This can also contribute to improving the accuracy of remaining-life estimation because of the many specimens available.

In this study, SP creep tests were carried out using miniaturized plate-type specimens removed from the HAZ and the base and weld metals of the welded joint of the boiler header, which had actually been used for around $250000 \mathrm{~h}$. The SP creep rupture data were correlated with the results obtained from the standard uniaxial creep tests, so that the SP creep test could be developed as a new procedure to evaluate the creep properties of welded joints. In addition, the decrease in creep rupture strength due to long-term 
Table 1. Chemical compositions (wt \%) of the base and weld metals.

\begin{tabular}{cccccccccccc}
\hline & $\mathrm{C}$ & $\mathrm{Si}$ & $\mathrm{Mn}$ & $\mathrm{P}$ & $\mathrm{S}$ & $\mathrm{Cr}$ & $\mathrm{Cu}$ & $\mathrm{Mo}$ & $\mathrm{As}$ & $\mathrm{Sb}$ & $\mathrm{V}$ \\
\hline Base metal & 0.15 & 0.26 & 0.50 & 0.012 & 0.0032 & 1.10 & 0.06 & 0.31 & 0.020 & 0.0036 & 0.01 \\
\hline Weld metal & 0.12 & 0.44 & 0.60 & 0.008 & 0.0080 & 1.27 & 0.08 & 0.50 & 0.018 & 0.0053 & 0.01 \\
\hline
\end{tabular}

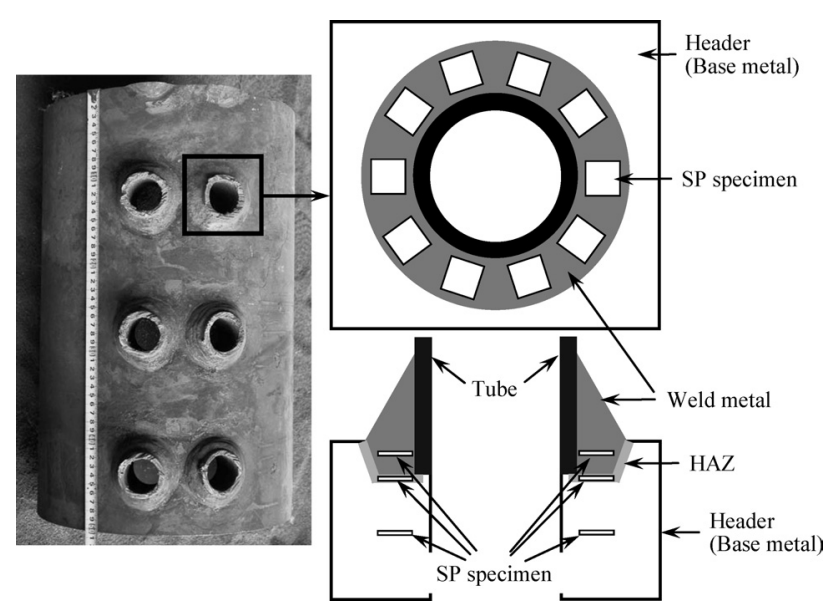

Fig. 1. Boiler header and schematic illustration showing the portions where the SP specimens were taken.

service exposure was examined from the perspectives of microstructural changes.

\section{Materials and Experimental Procedures}

\subsection{Materials}

The SP creep testing technique was applied to the welded joint between the boiler header and the heat exchanger tube (Fig. 1). The material was low alloy heat-resistant steel 1.0Cr-0.3Mo (KA-STPA21), which had been actually used as the header for around $250000 \mathrm{~h}$. It is presumed that the fillet weld was performed using the shielded metal ark welding (SMAW) process, although the detail is unclear because the plant had been constructed a long time ago. A similar composition filler metal of STBA23 was fed for the SMAW and the heat input for welding was estimated to be less than $3 \mathrm{~kJ} / \mathrm{mm}$ from the microstructural observation. Table 1 shows the chemical compositions of the base and weld metals. The operating conditions of the header are summarized in Table 2. The microstructure of each region was observed by optical, scanning electron and transmission electron microscopes respectively and the amounts of molybdenum and chromium in the solid-solution were also measured using the electrolytic extraction method.

\subsection{Small Punch Creep Tests}

Plate-type specimens of $10 \times 10 \times 0.65 \mathrm{~mm}$ were removed from the HAZ and the base and weld metals, respectively, as schematically illustrated in Fig. 1. The thickness of HAZ was around $2 \mathrm{~mm}$, sufficient to remove two specimens of thickness $0.65 \mathrm{~mm}$. However, it was very hard to cut the specimens from the fine grain HAZ (FGHAZ) and coarse grain HAZ (CGHAZ) individually, although both regions could be clearly distinguished by optical microscopy. Therefore, the specimen was removed from the mid section of the thickness of HAZ in the present study. Both the specimen surfaces were mechanically polished up to a $0.1 \mu \mathrm{m}$
Table 2. Operating conditions of the header.

\begin{tabular}{ll}
\hline Geometry & $\phi 324 \times \mathrm{t} 45.8 \mathrm{~mm}$ \\
\hline Operation time & $255,220 \mathrm{~h}$ \\
\hline Design temperature & $515^{\circ} \mathrm{C}$ \\
\hline Design pressure & $9.3 \mathrm{MPa}$ \\
\hline Hoop stress & $29 \mathrm{MPa}$ \\
\hline System stress & $48 \mathrm{MPa}$ (Max.) \\
\hline
\end{tabular}

alumina powder finish and the specimen's thickness was finally adjusted to $0.50 \mathrm{~mm}$.

A constant load was applied to the center of the specimen placed between the upper and lower dies through the $\mathrm{Si}_{3} \mathrm{~N}_{4}$ ball $(\phi 2.4 \mathrm{~mm})$ using the electric servo motor. The central deflection of the specimen was then monitored by measuring the displacement of the compression rod. All the tests were carried out in an argon gas atmosphere and the gas was continuously passed through during the tests to prevent severe oxidation of the specimen. In addition, a titanium wire mesh was wrapped around the specimen holder to take residual oxygen away from the atmosphere. The SP creep tests were performed at temperatures of 848 and $873 \mathrm{~K}$ and over a range of loads from 115 to $490 \mathrm{~N}$. Details of this SP creep testing technique and the data analysis are given in our previous paper. ${ }^{22}$ The standard uniaxial creep tests were also carried out using the base metal to verify the validity of the creep rupture strength evaluated by the SP creep test.

\section{Results and Discussion}

\subsection{Changes in the Microstructure by Long-term Ser- vice Operation}

Figure 2 shows the microstructures observed in the base metal, FGHAZ and CGHAZ. The base metal consisted of ferrite, and bainite and the block boundary or sub-boundary was partially disappeared, resulting in the recovery of bainite structure. On the other hand, the FGHAZ and the CGHAZ exhibited tempered bainetic structures. It was additionally observed that microvoids existed along prior $\gamma$ grain boundaries and some of them coalesced forming small intergranular cracking. Figure 3 shows an example of microvoids and/or grain boundary crack in the base metal. In some HAZ, as shown in Fig. 4, film-like (Fe, Mo) ${ }_{6} \mathrm{C}$ carbides, which cause the decrease in amount of solid-solution element of molybdenum and are well known as the final equilibrium carbide in low-alloy steel, ${ }^{23-25)}$ precipitated along prior $\gamma$ grain boundaries. This result suggested a significant deterioration of the microstructure in the HAZ. Based on the result of the electrolytic extraction analysis, it was revealed that the amounts of chromium and molybdenum in the solid-solution were only $0.58 \%$ and $0.11 \%$, respectively.

Figure 5 shows the micro Vickers hardness measured 

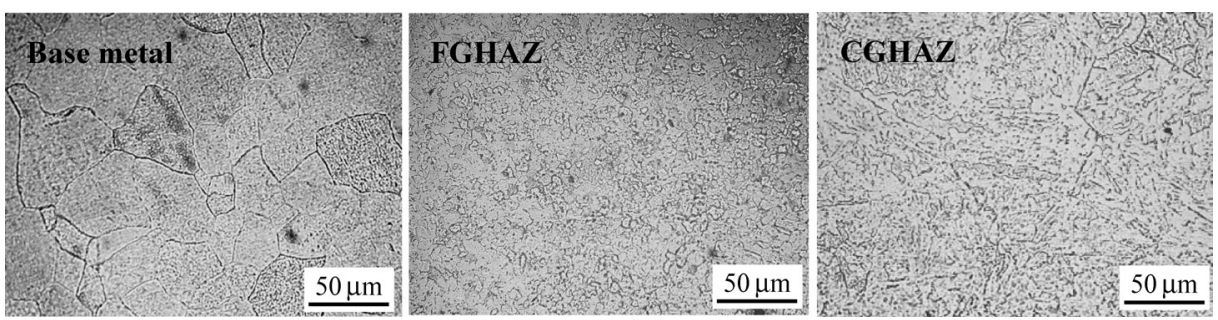

Fig. 2. Optical micrographs of the base metal, FGHAZ and CGHAZ.

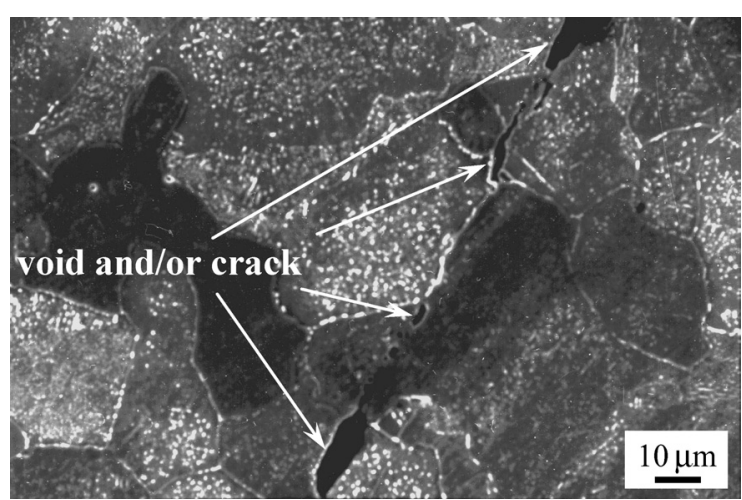

Fig. 3. SEM micrograph of microvoids and/or G.B. crack in the base metal.

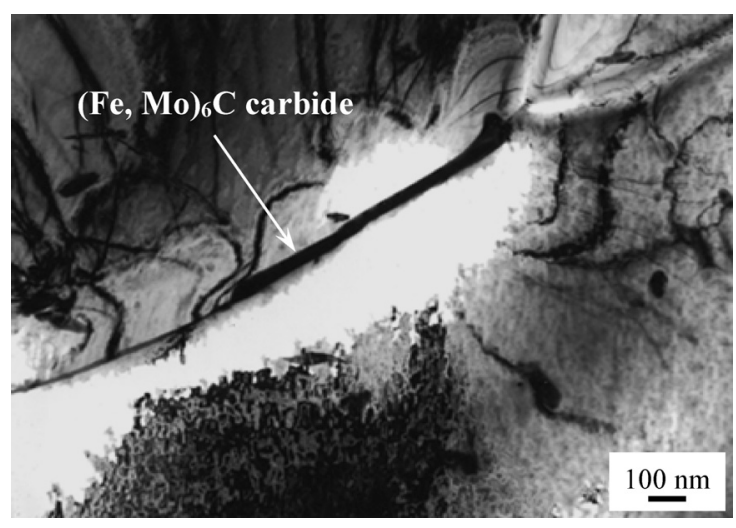

Fig. 4. TEM micrograph of film-like $(\mathrm{Fe}, \mathrm{Mo})_{6} \mathrm{C}$ carbide precipitated along G.B.

from the base metal through to the weld metal under a load of $9.8 \mathrm{~N}$. The measurements were conducted along three different lines and no significant differences were revealed between the results. It can be seen that the hardness of the weld metal is around $60 \mathrm{HV}$ higher than that of the base metal, with no significant softening occurring in the HAZ. This higher hardness of the weld metal is considered likely to be attributable to the grade of steel, i.e. the higher concentrations of molybdenum and chromium.

\subsection{SP Creep Properties}

Figure 6 shows the examples of time-central deflection curves (Fig. 6(a)) and time-deflection rate curves (Fig. 6(b)) measured on the base metal under various creep conditions. As reported in previous studies, ${ }^{13,22)}$ the overall shapes of both curves are qualitatively similar to those obtained from a conventional uniaxial creep test, although the instantaneous deflection is very significant at the time of

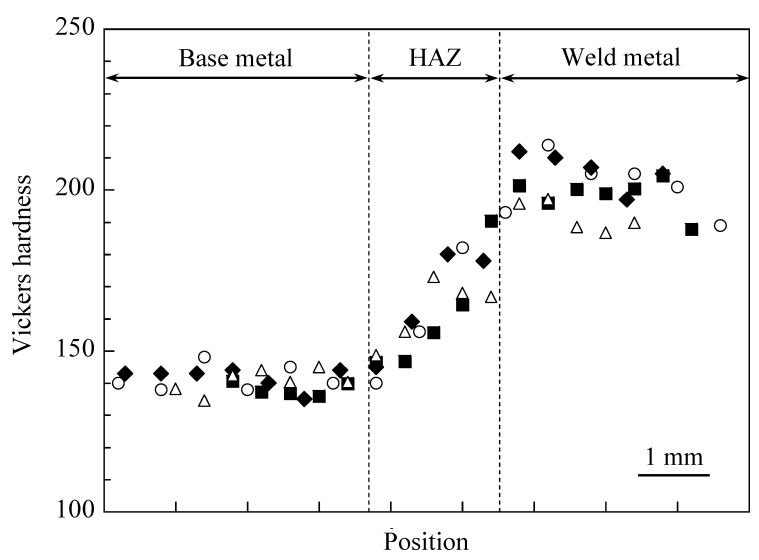

Fig. 5. Distribution of Vickers hardness measured on the welded joint.
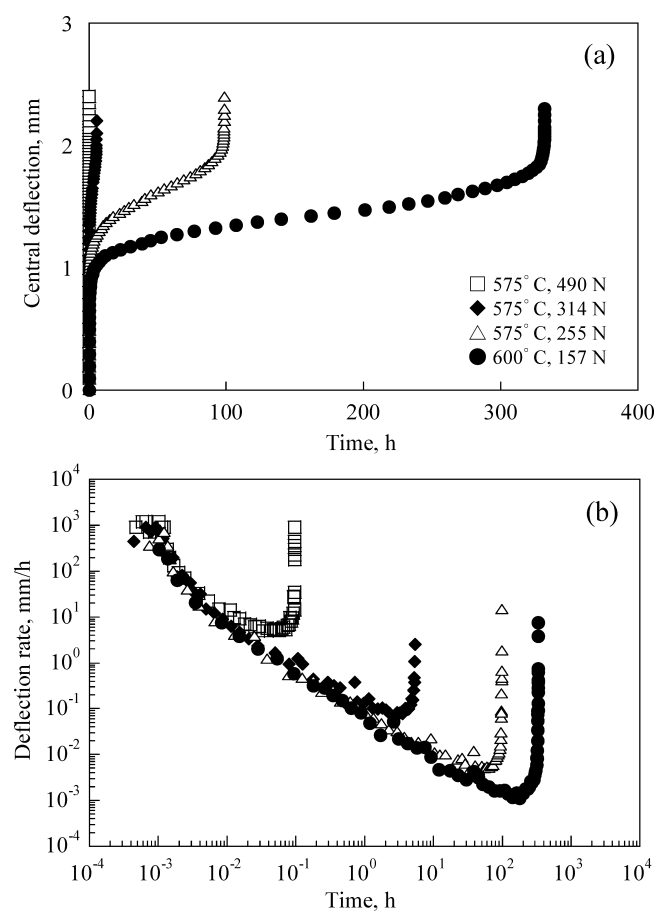

Fig. 6. SP creep curves measured on the base metal at various conditions.

initial load application in the case of the SP creep test. This significant deflection is attributable to the plastic bending deformation rather than the creep deformation. The creep rate at the primary creep regime shows almost no variation, irrespective of the creep conditions, however the minimum creep rate decreases at the mild creep condition, resulting in the increase in the rupture time.

The time-central deflection curves measured on the HAZ at two different creep conditions are given in Fig. 7, along- 

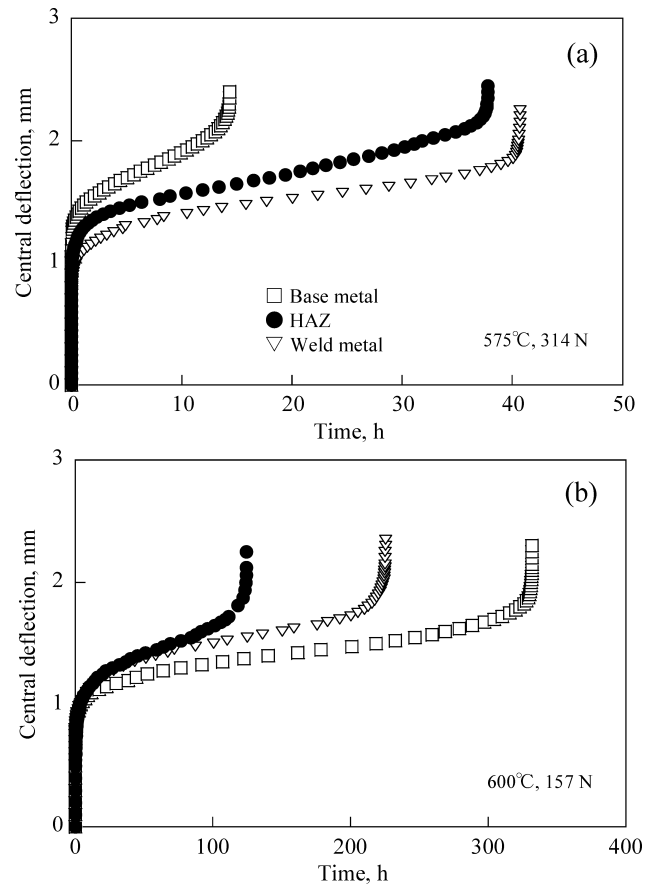

Fig. 7. SP creep curves measured on the base metal, HAZ and weld metal.

side the results of the base and weld metals. It is clearly evident that the rupture time of the base metal is the shortest at the condition of $575^{\circ} \mathrm{C} / 314 \mathrm{~N}$. However, it is longer than the others at $600^{\circ} \mathrm{C} / 157 \mathrm{~N}$ to the contrary and the HAZ has the shortest rupture life. This change in the relative rupture strength appears closely associated with the strength (hardness). In general, at relatively high creep stress levels where the strain rate is high, the creep test result reflects more significantly the tensile properties than the time-dependent creep properties. In addition, it is known that the hardness corresponds to the tensile strength and there is an almost linear correlation between them in some steels. ${ }^{26)}$ As shown in Fig. 5, the hardness of the base metal is around 140HV, namely lower than those of the HAZ and weld metal. This lower hardness of the base metal is considered to result in inferior creep rupture strength at a high load level, i.e. $575^{\circ} \mathrm{C} / 314$ N. Therefore, Fig. 6(a) may reflect more remarkably the difference in tensile strength rather than creep strength.

The results of the creep rupture test are summarized in Fig. 8, where the load is plotted as a function of the Larson-Miller parameter. This parameter is usually used to arrange the rupture data of uniaxial creep tests and is expressed as follows:

$$
\mathrm{LMP}=(T+273)(\log t+C)
$$

where, $T$ is the test temperature $\left[{ }^{\circ} \mathrm{C}\right], t$ is the time to rupture [h] and $C$ is a constant $(C=20)$. At the high load level $(F>255 \mathrm{~N})$, as mentioned above, the HAZ and weld metal have higher rupture strength than the base metal. It is very important to emphasize that the rupture strength of HAZ is inferior to others at a low load level and the fact that this difference has the tendency to become more pronounced with decreasing load.

The minimum deflection rates measured on the three materials are plotted as a function of the rupture times in Fig.

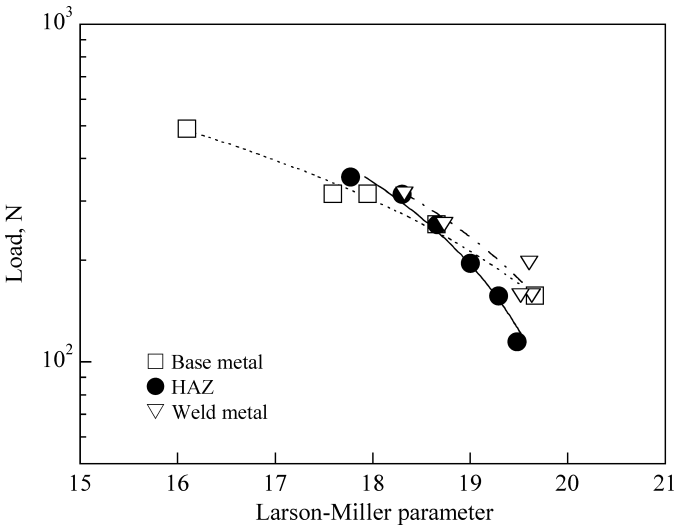

Fig. 8. Results of creep rupture tests obtained from the base metal, HAZ and weld metal.

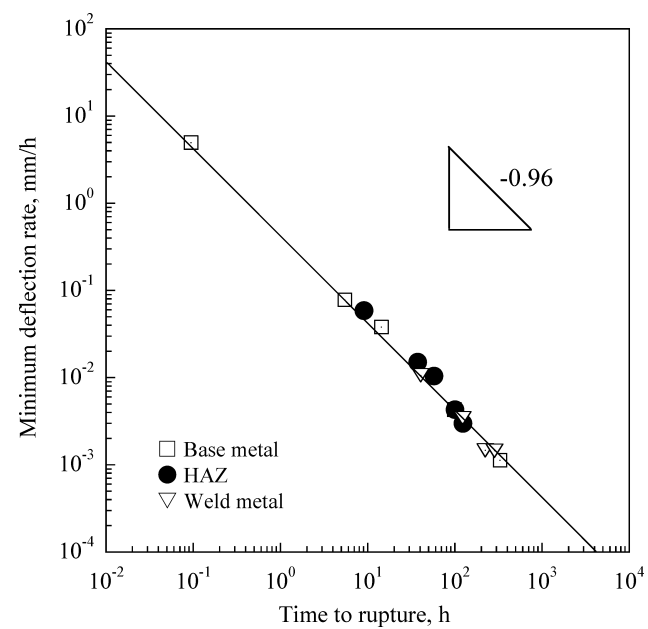

Fig. 9. Relationship between minimum deflection rate and time to rupture.

9. Here, the minimum rate correlates well to the rupture time with a slope of about -1 , irrespective of the material and test conditions. This correlation is well known as the Monkman-Grant law and indicates that the deformation mechanism of SP creep is closely associated with the fracture mechanism, as well as those of uniaxial creep.

\subsection{Damage Evaluation by SP Creep Test}

Creep properties determined from a standard uniaxial test have long been utilized for the design and remaininglife prediction of high-temperature components. With this in mind, it is essential to find out the equivalence of the SP creep test to the uniaxial creep test in order to apply this SP creep testing method to the damage evaluation and/or remaining-life assessment of the actual components. Sugimoto et al. ${ }^{22)}$ investigated the correlation between the load of the SP creep test, $F$, and the stress of the uniaxial test, $\sigma$, to quantitatively establish the correlation between both test data. Consequently, it was revealed that the following correlation existed between them:

$$
F=2.4 \sigma \text {. }
$$

The coefficient of stress conversion, $\alpha=2.4$, was determined such that the creep rupture data curves of the SP and uniaxial creep tests overlapped each other. It was notewor- 


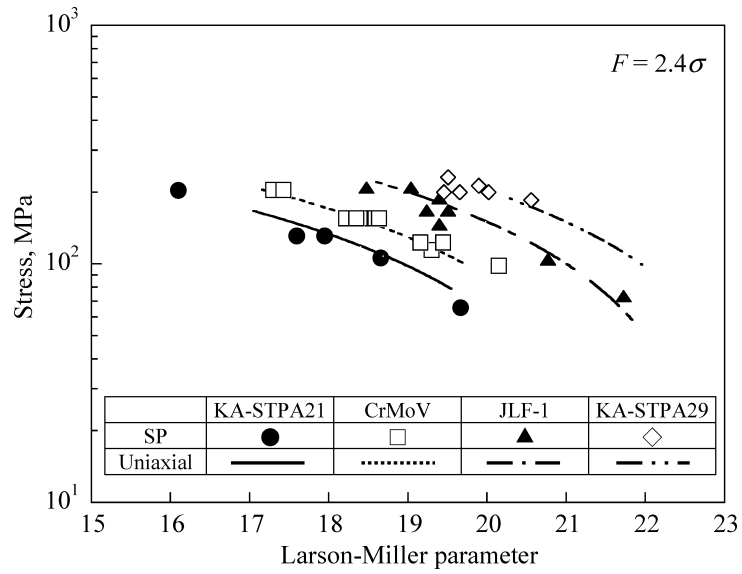

Fig. 10. Results of uniaxial and SP creep tests after converting load to stress.

thy that this coefficient showed no significant change among the ferritic steels, of which the Vickers hardness was lower than $260 \mathrm{HV}^{27)}$ This result indicated that the creep rupture strength of the uniaxial creep test could be estimated via the SP creep test, irrespective of the kind of steel, assuming the steel concerned to have relatively high ductility.

Figure 10 shows the rupture data of base metal determined by the SP and uniaxial creep tests, alongside the results of three other ferritic steels, namely $\mathrm{CrMoV}$ cast steel, ${ }^{22)}$ low activation $9 \% \mathrm{Cr}$ ferritic steel for fusion reactor $(\mathrm{JLF}-1)^{28)}$ and KA-STPA29. ${ }^{13)}$ The solid, dotted and dashed lines respectively indicate the results of uniaxial creep tests, while the closed and open symbols are those of the SP creep test. The loads of SP creep tests were converted to stress by Eq. (2). The present results of the base metal obtained from the SP creep test correlate relatively well to that from the uniaxial creep test, as well as three other steels. This result suggests that Eq. (2) is also available to $1.0 \mathrm{Cr}-0.3 \mathrm{Mo}$ (KA-STPA21) for converting the results of the SP creep test to those of the uniaxial test.

Figure 11 shows a comparison between the creep rupture data obtained from the present welded joint and the uniaxial creep data of STBA20 ${ }^{29)}$ and STBA22, ${ }^{30)}$ which are used in place of the virgin base and weld metals, respectively. The results of the welded joint were determined by the SP creep test and the loads were converted to stresses by Eq. (2). The creep rupture strength of the base and weld metals are inferior to those of STBA 20 and STBA22, i.e. their virgin steels when exposed to high stress levels. However, these decreases in strength tend to be smaller as the stress decreases, with smaller differences between the rupture lives of the base and weld metals and the virgin steels at the actual maximum working stress of $48 \mathrm{MPa}$. On the other hand, the decrease in rupture strength of HAZ is inclined to stand out with decreasing stress to the contrary and its rupture life when exposed to working stress is significantly shorter than that of virgin steel. This result seems attributable to the above-mentioned microstructural changes such as the formation of film-like $(\mathrm{Fe}, \mathrm{Mo})_{6} \mathrm{C}$ carbides and the resultant decrease in solid-solution element. It may reflect the Type IV damage. The remaining-lives of the HAZ, the weld metal and the base metal were calculated from each Larson-Miller parameter versus stress curve (Fig. 11), based

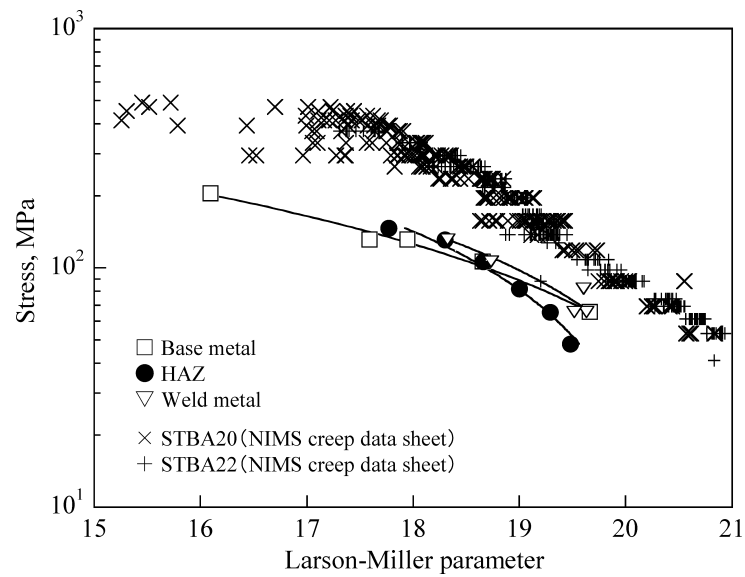

Fig. 11. Comparisons between results obtained from this study and NIMS creep data.

on the assumption of $48 \mathrm{MPa}$ of working stress. As a result, their remaining-lives were estimated at around 66000 , 260000 and $280000 \mathrm{~h}$, respectively, and the HAZ has already consumed about $80 \%$ of the lifespan.

Accordingly, the creep properties of each portion, i.e. the HAZ and the weld and base metals, can be evaluated using the SP creep test, which is a very useful technique for estimating the remaining-life of welded joints. However, the present results measured on the HAZ reflect the averaged properties of CGHAZ and FGHAZ. The degradation could be evaluated in further detail if the SP specimens were removed from both regions individually. There may be a need to improve the procedure for sampling small specimens more efficiently and to develop the SP creep testing technique using further miniaturized specimens.

\section{Conclusions}

The SP creep tests were carried out using plate-type specimens taken from the HAZ and the base and weld metals of the welded joint of the boiler header, which had been actually used for around $250000 \mathrm{~h}$. The SP creep rupture data were correlated with the results obtained from the standard uniaxial creep tests for the purpose of developing the SP creep test as a new procedure to evaluate the creep properties of welded joints. In addition, the decrease in creep rupture strength by a long-term service exposure was examined from the perspectives of microstructural changes. Based on the present investigation, the following conclusions can be drawn:

(1) The final equilibrium film-like $(\mathrm{Fe}, \mathrm{Mo})_{6} \mathrm{C}$ carbides precipitate along the prior $\gamma$ grain boundaries in the HAZ. This result indicates a significant deterioration of the microstructure in the HAZ.

(2) The SP creep strength of the HAZ is inferior to the base and weld metals at low load levels. This decrease in strength is attributable to the above microstructure and may reflect the Type IV damage.

(3) The correlation between the results of the base metal obtained from the SP and those from the standard uniaxial creep tests agrees with the correlation reported in an earlier study. In other words, the ratio of the load of SP creep test, $F$, and the stress of uniaxial test, $\sigma$, is 2.4 when both rupture curves (Larson-Miller parameter versus load 
or stress curves) are overlapped with each other.

(4) The rupture strength of the HAZ is inferior to those of STBA20 and STBA22, which are used in place of the virgin steel. This lower strength is inclined to stand out more with decreasing stress.

(5) The remaining-lives of the HAZ, the weld metal and the base metal are estimated to be around 66000 , 260000 , and $280000 \mathrm{~h}$, respectively, and the HAZ has already consumed about $80 \%$ of its lifespan.

\section{Acknowledgements}

This work was partially supported by the Japan Ministry of Education, Science, Sports and Culture under Grants-inAid for Scientific Research (Shin-ichi Komazaki, No. 15686005).

\section{REFERENCES}

1) Thermal and Nuclear Power Engineering Society: J. Therm. Nucl. Power, 51 (2000), 492.

2) F. Masuyama, M. Matsui and N. Komai: Key Eng. Mater, 171-174 (2000), 99.

3) M. Matsui, M. Tabuchi, T. Watanabe, K. Kubo, J. Kinugawa and F. Abe: ISIJ Int., 41 (2001), S126.

4) Y. Hasegawa, T. Muraki and M. Ogami: Tetsu-to-Hagané, 92 (2006), 609.

5) Y. Hasegawa, T. Muraki and M. Ogami: Tetsu-to-Hagané, 92 (2006), 618.

6) A. Iseda, Y. Sawaragi and K. Yoshikawa: Tetsu-to-Hagané, 77 (1991), 582.

7) M. Tabuchi, T. Watanabe, K. Kubo, M. Matsui, J. Kinugawa and F. Abe: J. Soc. Mater. Sci., Jpn., 50 (2001), 116.

8) J. Kameda and O. Buck: Mater. Sci. Eng., 83 (1986), 29

9) T. Misawa, T. Adachi, M. Saito and Y. Hamaguchi: J. Nucl. Mater., 150 (1987), 194
10) Y.-H. Joo, T. Hashida and H. Takahashi: J. Test. Eval., 20 (1992), 6.

11) X. Mao, T. Shoji and H. Takahashi: J. Test. Eval., 15 (1987), 30.

12) X. Mao and H. Takahashi: J. Nucl. Mater., 150 (1987), 42.

13) S. Komazaki, S. Liu, I. Kwon, T. Hashida, H. Takahashi and H. Nakajima: Trans. Jpn. Soc. Mech. Eng. A, 70 (2004), 273.

14) S. Liu, S. Komazaki, I. Kwon, T. Hashida, Takahashi and H. Nakajima: Trans. Jpn. Soc. Mech. Eng. A, 70 (2004), 628.

15) S. Komazaki, T. Shoji and K. Takamura: J. Eng. Mater. Technol., 127 (2005), 476

16) S. Komazaki, A. Koyama and T. Misawa: Mater. Trans., 43 (2002), 2213.

17) J. Isselin, S. Wang, S. Komazaki and T. Shoji: Key Eng. Mater, 297-300 (2005), 980.

18) J. D. Parker and J. D. James: Developments in a Progressing Technology, PVP-Vol. 279, ASME, New York, (1994), 167.

19) S. Tettamanti and R. Crudeli: Proc. Int. Symp. on Case Histories on Integrity and Failures in Industry, EMAS, West Midlands, UK., (1999), 895

20) S. Komazaki, T. Hashida, T. Shoji and K. Suzuki: J. Test. Eval., 28 (2000), 249

21) M. L. Saucedo-Munoz, S. Komazaki, T. Takahashi, T. Hashida and T. Shoji: J. Mater. Res., 17 (2002), 1945.

22) T. Sugimoto, K. Doki, S. Komazaki and T. Misawa: Tetsu-toHagané, 91 (2005), 408.

23) R. G. Baker and J. Nutting: J. Iron Steel Inst., 192 (1959), 257.

24) K. W. Andrews, H. Hughes and D. J. Dyson: J. Iron Steel Inst., 210 (1972), 337.

25) A. Afrouz, M. J. Collins and R. Pilkington: Met. Technol., 10 (1983), 461.

26) D. Tabor: Hardness of Metals, Clarendon Press, Oxford, (1951), 107.

27) T. Sugimoto and S. Komazaki: Proc. Annual Meeting of the JSME/MMD, JSME, Tokyo, (2005), 105.

28) T. Nakata, S. Komazaki, Y. Kohno, K. Shiba, A. Kohyama and T. Hashida: J. Jpn. Inst. Met., 70 (2006), 130.

29) National Institute for Materials Science: NIMS Creep Data Sheet No. 20B, NIMS, Tokyo, (1994).

30) National Institute for Materials Science: NIMS Creep Data Sheet No. 1B, NIMS, Tokyo, (1996). 